\title{
Present challenges for future water sustainable cities: a case study from Italy
}

\author{
L. Bonzanigo and G. Sinnona \\ Sustainable Development Programme, Fondazione Eni Enrico Mattei (FEEM), Isola di San Giorgio Maggiore, \\ 30124 Venezia, Italia \\ Correspondence to: L. Bonzanigo (laura.bonzanigo@feem.it)
}

Received: 26 March 2013 - Published in Drink. Water Eng. Sci. Discuss.: 3 June 2013

Revised: 30 January 2014 - Accepted: 18 March 2014 - Published: 9 April 2014

\begin{abstract}
The global population is increasingly concentrated in cities. Cities and urban areas face many challenges - economic, social, health and environmental - which are often exacerbated by an increase in the frequency of natural disasters. Together, these challenges call for a shift towards sustainable cities which reduce their impact on the surrounding environment, whilst at the same time succeeding to make resources available to their increasing number of inhabitants. This study explores the state of the art of water management practices of the highly urbanised Northern Italian region and plans and scope for the future development of water management. Although the region is at present not under severe water stress, recently some cities faced water scarcity problems and were forced to implement water rationing. We assessed the vulnerability of Parma and Ferrara to a water crisis, together with the regular and emergency adaptation measures already in place, and the forecast for the near future. In two workshops, the authors adapted the Australian concept of water sensitive urban design for the Italian context. Although the population remains generally unaware of the impact of the two latest severe drought events (2003 and 2006/7), many adaptation measures towards a more sustainable use of the water resource are already in place - technically, institutionally, and individually. Water managers consider however that the drastic and definite changes needed to integrate the urban water management cycle, and which minimise the ecological footprint of urban spaces, lay far in the future.
\end{abstract}

\section{Introduction}

The effects of global warming because of climate change is already increasing vulnerability of several urban areas around the world, through raising sea levels, inland floods, more frequent droughts, periods of increased heat, and the spread of diseases. In 2003, more than 70000 people died in Europe from a severe heat wave (The World Bank, 2010). These kinds of extreme events will increase in coming years. Due to climate change, the access to basic urban services, especially those linked to water supply, is expected to become more difficult, worsening citizens' quality of life. Urban planned need cities' infrastructure to be able to contrast these threats and ensure that the main services continue to be provided to its inhabitants (i.e. water supply and transport, amongst others).
Cities are uniquely equipped to deal with the challenges they face (C40 Cities, 2011). In some places, like Australia, the widespread realisation of the significance of climate change stimulates citizens' aspirations to ensure that cities reduce their ecological footprint in order to become more sustainable, and to improve their structure and function to make them more liveable in. Yet, change seems slow: many cities still face ongoing investments in the conventional way.

Climate change affects all continents to different extents. Although the focus is primarily on vulnerable cities in developing countries, cities in Europe are also affected by climate change related disasters. The frequencies of both droughts and severe flooding are increasing. In the last decade, 2003 was the hottest summer since 1850 , with temperatures 20 $30 \%$ higher than in normal years. 40000 people died because of the heat; alpine glaciers lost $10 \%$ of their total mass, 
power interruptions occurred frequently, many crops failed, and so forth. Similarly, in 2006/7, in Southern Europe precipitation fell by $89 \%$ in January and $50 \%$ in February. Italy is not immune either and suffers from slight, but important climate variations that lead to the need for a modification of the standard approach towards the management of natural resources, stimulating the implementation of new adaptation measures.

This article explores the state of the art of water management practices of a highly urbanised Northern Italian region. The research was conducted as part of the IWRMnet Water2Adapt project ${ }^{1}$. Although Emilia-Romagna does not generally suffer from severe water stress, recently some cities faced water scarcity problems and at times they were forced to implement water rationing. Moreover, water quality is increasingly affecting water availability. In the Po river basin, pollution is a critical issue for many groundwater aquifers, which constitute the primary water source for several urban areas (Carrera et al., 2013). In the two case studies, we assessed their vulnerability to water crises (past and future), together with ordinary and emergency adaptation measures already in place and the forecast for the near future. The next section describes the case studies and justifies their choice; and then the methods section discusses how the authors explored the vulnerability of the two cities and possible measures to ensure water sustainability. Thirdly, the article examines the outcomes of the workshops.

\section{Materials and methods}

This article focuses on droughts in the Emilia-Romagna region, both because of the region's differentiated climate between east and west, and for its fast growing urban areas. Emilia-Romagna has the largest number of cities in Italy ranked in terms of population: it has nine cities with more than 100000 inhabitants, seven of the most populous cities in Italy and ten amongst the first fifty. The case studies in the Water2Adapt project were based on two "medium-size" cities in the region, namely, Parma (West) and Ferrara (East), which present similar historical characteristics whilst having very dissimilar water management practices. We studied their reactions to the two most serious droughts of the last ten years, namely 2003 and 2006/7, and their preparations for longer periods of water scarcity expected in the future due to climate change patterns.

These cities were chosen because of (i) the dependency of each city on a single water source, namely groundwater and the Po river respectively; (ii) their different categories and levels of vulnerability, with Ferrara at risk primarily due to the shortage of water, even during short term droughts, whereas Parma is more sensitive to water quality degeneration and is not so vulnerable to brief water scarcity events.

\footnotetext{
${ }^{1}$ http://www.feem-project.net/water2adapt/
}

Ferrara is located near the Po river delta. It has 135369 residents and an average population density of 334.9 per $\mathrm{km}^{2}$ (ATO6 Ferrara, 2006). Dependence of Ferrara on the Po River ensures on the one hand nearly unlimited water availability, except during an exceptional drought event (such as in 2003), whilst on the other hand however, it requires advanced water treatment plants, especially due to Ferrara's position along the river, downstream of other significant urban areas. In addition, due to the local topography, pumps are needed to distribute water in the network. The reliance on pumping increases the vulnerability of the network to a varying abstraction of water: when the river levels drop, the pressure in the pipes cannot be maintained and they can be damaged.

The Municipality of Parma has 179000 residents and a population density of 699 inhabitants $\mathrm{km}^{-2}$. The city acquires nearly all its water from groundwater sources, some of which at present have an annual deficit. Of the two well fields that supply Parma, the southern field is already polluted with nitrates of agricultural origin (up to $50-60 \mathrm{mg} \mathrm{L}^{-1}$ ) (ATO2 Parma, 2010). The best water originates from city wells, whose quality is protected both by law and by the southern well field, which absorbs any pollution before the water reaches the city wells (Ferrari and Spina, 2011). Parma water managers are assessing the feasibility of diverting water from the Taro and Cerno rivers, which are of acceptable quality according to the regional Water Laws and could potentially supply 280000 users with $800 \mathrm{~L} \mathrm{~s}^{-1}$.

Given that water comes primarily from aquifers, it is difficult to estimate the sustainability of present pumping patterns, particularly when there is independent abstraction for industrial and/or agricultural uses, which often compete with requirements for domestic consumption. Recent studies by the Regional Environmental Agency however, underline a yearly water deficit of $1221800 \mathrm{~m}^{3}$ at a provincial level (Provincia di Parma, 2003). Although withdrawals of about $46.3 \mathrm{Mm}^{3}$ in 2008 by the main water suppliers' withdrawals accounted for $33 \%$ of total water available, the study estimates that the system is not able to respond in a sustainable manner to a potential increase in water needs.

The study aimed to both assess the vulnerability of the two cities to drought, and measures towards a more sustainable and resilient water consumption, which in turn may reduce the exposure of a city to water scarcity. For this paper, the authors adopt the IPCC definition for vulnerability. "The degree to which a system is susceptible to, or unable to cope with, adverse effects of climate change, including climate variability and extremes. Vulnerability is a function of the character, magnitude, and rate of climate variation to which a system is exposed, its sensitivity, and its adaptive capacity" (IPCC, 2001).

In order to explore vulnerability, the authors built on the work of Milman and Short (2008). In their assessment of the sustainability of urban water systems, they identify a new indicator, Water Provision Resilience (WPR), which defines 
the vulnerability of a water system to providing water, and thus gives useful information for solving the basic shortcomings of the system. It is beyond the scope of this paper to calculate the WPR for the two case studies. However, the authors adopted Milman and Short's identification of six critical aspects of urban water management for the measurement of WPR: supply, infrastructure, service provision, finances, water quality and governance. In the authors' opinion, consideration of these factors introduces resilience to the analysis of sustainability (Milman and Short, 2008). After a preliminary assessment of the two case studies, the authors clustered the six indicators in the following categories: water source, structural measures, institutional and political dimensions, and a sound communication plan. As a consequence, the most important factors for assessing past, present, and future vulnerabilities future vulnerability are: diversification of water sources, infrastructural measures such as desalinization, water reuse, long distance pipe-lines from remote sources, institutional and political framework to regulate the price of water and the related investments to reduce losses, and communication strategies to increase awareness of a proper use of domestic water.

As a framework for the analysis of policies and actions taken by the two cities towards sustainable water management, we applied the Australian concept of water sensitive urban design (WSUD), so far, little explored in European contexts. WSUD is a "holistic approach to the planning and design of urban development that aims to minimise impacts on the natural water cycle and protect the health of aquatic ecosystems" (McAuley and McManus, 2009). In other words, WSUD seeks to address the deficiencies in traditional urban water management practices by minimising the hydrological impacts of urban development in the surrounding environments. WSUD in Australia has evolved from its early association with stormwater management to provide a broader framework for sustainable urban water management. It provides a common and unified method for integrating the interactions between the built form (including urban landscapes) and the urban water cycle (Wong, 2006). In Australia, WSUD is increasingly practiced in new urban greenfield development areas and urban renewal developments linked to a broader Ecologically Sustainable Development agenda. Ecologically Sustainable Development in Australia can be described as going beyond the protection of the environment from the impacts of pollution, to protecting and conserving natural resources (Wong, 2006).

Key transition factors for WS cities are: (i) interorganisational collaboration and coordination community participation; (ii) uniform regulatory framework and processes; (iii) organisational capacity; and (iv) organisational commitment (Brown and Farrelly, 2007). This article focuses primarily on public sector development and major subdivisions. At the subdivision scale, there is indeed the opportunity, for instance, to undertake large-scale potable wa- ter substitution, for example using wastewater recycling or stormwater harvesting and reuse.

In order to achieve these objectives, the project organised one workshop in each city with political and technical representatives, where weaknesses of their organisation were assessed through brainstorming sessions based on the methods described above. During the meetings, discussion revolved around how to make the four transition factors operational, by focusing on priorities of water use, social risks of interruptions to the water supply, categories of intervention already in place in the two cities, and future actions planned and/or envisaged (Fig. 1). The main outcome of the workshops was the development of a new water management policy to address present shortcomings through the best practices identified.

\section{Results and discussion}

Neither Parma nor Ferrara experienced significant water shortages during the water crises in 2003 and 2006-2007. However, the short droughts of 2003 and 2006/7 revealed vulnerability of both cities to major and lasting drought events. Moreover, there emerged the interconnection of two concepts we initially thought as being separate. It appeared that water managers are increasingly implementing some of the WSUD principles regarding future crises, in order to reduce the cities' vulnerability. For instance, because of the antiquity of the centres of the majority of Italian cities, rainwater harvesting is only possible in new areas, and even there storage is a problem due to lack of space. However, the rehabilitation of the wells in Parma demonstrates a clear move towards the minimisation of water consumption patterns and the maximisation of water re-use, whenever possible, which would improve the city's ecological footprint. Nevertheless, a specific application of WSUD principles needs a very critical level of water scarcity, as has occurred in Australia, in order to prompt people to support this approach. In the Po river, droughts are still marginal to citizens' lives and hence the concept is harder to justify in political terms.

Below, there follows a description of the implications of the four selected factors for the management of previous water crisis events, the strengths and weaknesses of the factors, and the future direction of their development.

Firstly, the cities' water source seems to have been the main determining factor. The public water supply in Parma comes from groundwater; thus the effects of drought are delayed, and short-lasting drought events do not lead to immediate water shortages. In Ferrara too, the amount of water diverted from the Po river (av. $1 \mathrm{~m}^{3} \mathrm{~s}^{-1}$ ) is negligible compared to the average river flow $\left(1540 \mathrm{~m}^{3} \mathrm{~s}^{-1}\right)$ even under drought conditions (environmental flow: $240 \mathrm{~m}^{3} \mathrm{~s}^{-1}$ ), and hence it is unlikely that the city will run out of water. However, experts in both cities admit that their reliance on a single water source would significantly increase the risk should a severe water crisis materialise (whether drought or pollution). 


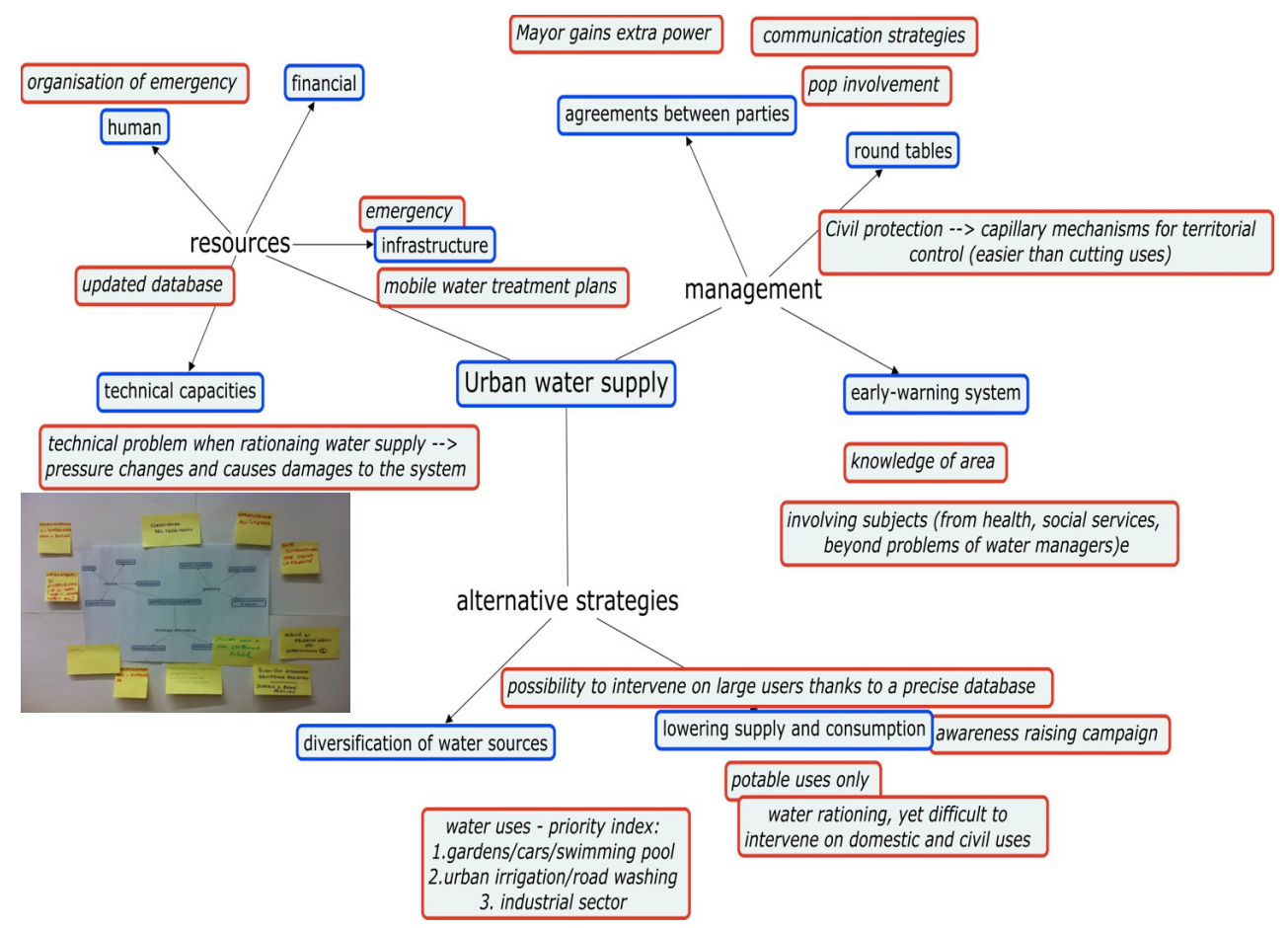

Figure 1. Conceptual map of Parma water supply's vulnerability as emerged during the workshop.

Parma's aquifers are increasingly polluted, which would hinder the city's supply in the future unless action is taken. Ferrara would also suffer, primarily from a water quality crisis. Therefore, the differentiation of water sources remains a priority for both municipalities. In Ferrara, participants suggested that they should invest more in a connection between networks, which would drastically reduce the city's vulnerability to drought as it would add another source to that of the Po river. Parma's water managers have several plans to manage emergencies, which include the diversification of water sources using an aqueduct, which would take water to Parma from a source $35 \mathrm{~km}$ away.

Secondly, structural measures in both the long- and shortterm would increase the flexibility of the two water systems. Recent droughts, although they did not affect the water supply severely, initiated a whole set of adaptation measures to reduce the cities' long-term vulnerability through good management. In Parma, after the 2006/7 droughts, the Municipality approved a plan for the rehabilitation of old, disused wells for non-potable water uses (including urban irrigation, road and sewage washing, fire fighting, construction sites, and so forth). On the one hand, this led to water and economic savings (such as energy for pumping and treating water for nonpotable uses), whilst on the other hand, it marginalised the risk of pollution spillage to the deep aquifer through these wells, which are often the drivers of pollution diffusion. The diversification of the water sources mentioned above remains top of the list of long-term measures. Effort would focus on the construction of dual systems for rainwater and black water, in order to maximise the potential for reuse, as well as reducing losses in the network up to a maximum of $20 \%$.

If water supply to the city of Ferrara suddenly failed, it would be necessary to use 5-6000 tank lorries per day to limit the impact on the population! In Ferrara, during the drought event of 2003, the river level fell below the abstraction point. In both the 2003 and 2006/7 droughts, water suppliers installed floating rafts, provided by Civil Protection, in the centre of the river to ensure sufficient water supply despite the critical water levels. Since then, such structures have been utilised twice in summer periods, although they do not constitute a permanent solution for a falling river level. In 2007 the pumps of one of the two diversion structures were extended so that water can be withdrawn at lower levels too.

Thirdly, our stakeholders all agreed that the institutional and political dimensions played a crucial role in avoiding the impacts of severe drought. During water crises, the Mayor acquires emergency powers and can impose restrictions on certain water uses. Both cities agree on the order in which certain uses should be eliminated during critical events: (i) private gardening, car washing, swimming pools, as they did in Parma in August 2007 in southern suburbs of the town; (ii) irrigation of urban areas, road washing; (iii) industrial uses (although large industries that consume more than $100000 \mathrm{~m}^{3}$ year $^{-1}$ usually have their own wells. One example is Barilla, worldwide one of the largest pasta producers). In case of a water emergency, the population would 
be involved through a concerted awareness raising campaign, while social services, medical personnel and so forth would be mobilised. The problem would gain an interdisciplinary dimension, beyond the water management company's sole authority. It would be feasible to intervene in the water consumption of large users (industries) thanks to the existence of a precise database of all industrial water consumption, which belongs to the Region. In these instances, industries with a private well would have to stop production and make their water available for civil uses. According to experts present at the workshop, these measures would be feasible and sufficient to minimise the impacts of a short and intense drought.

Moreover, together with Civil Protection, when the main water source fails, mayors try to acquire water elsewhere, if possible. This is a preferred solution than to cut usage altogether, which often damages treatment plants and the whole supply network due to large variations in pressure. Yet, it is only possible if the various users and political actors work together in a coordinated fashion, regulated by a legitimate authority - in this instance, the "Cabina di Regia" (emergency decision-making board) called for by the River Basin Authority. A detailed analysis of the decision-making process during an emergency lies beyond the scope of this paper, yet the "Cabina di Regia" is unanimously recognised as a determining factor for the management of water crises. Water authorities and supply companies are drafting new emergency plans, which include who and what organisations to contact (provinces, government, River Basin Authorities, ...) and short-term interventions at the local level: such as tanklorries, plastic bags containing water, and so forth.

Finally, a sound communication plan is crucial, including both prevention and reaction mechanisms. For example, awareness-raising campaigns are crucial for cutting water consumption and stimulating a more sensitive behaviour on the part of not only citizens, but other urban users too (commercial and industrial organisations, urban agriculture, ...). The local administrators are aware of the fact that all technical adaptation and mitigation measures will not have a significant impact if they do not come with awareness and information campaigns directed at citizens and local users, in order to change their consumption patterns. In Parma, several campaigns are aimed at reducing individual consumption from 200 to less than $150 \mathrm{~L} \mathrm{~d}^{-1}$ through events involving children, advertising posts, and events focused on water issues. As a reaction mechanism, much attention focuses on early-warning systems, crucial for a prompt response to a crisis - particularly if linked to a sound institutional structure that can take prompt action. Although these systems are more prominent for floods and pollution crises, drought sensors are currently being implemented by the regional environmental agency, which has a dedicated website on its monitoring system. Stakeholders, despite their overall satisfaction with present communication strategies, have highlighted the need to exploit TV and radio more, although these - and especially the former - require the intervention of the national govern- ment,. Better cooperation amongst "colleagues" in the water sector is also important, as this has not been satisfactory in the past, according to the institutions themselves. Nevertheless, all participants claim that Emilia-Romagna still remains the leader and coordinator in Italy due to its tradition of research and investments at district level.

\section{Conclusions}

This study explores the state of practice of water management of the highly urbanised Northern Italian region and plans and scope for the future development of water management. Although the region is at present not under severe water stress, recently some cities faced water scarcity problems and were forced to implement water rationing. We assessed the vulnerability of Parma and Ferrara to a water crisis, together with the regular and emergency adaptation measures already in place, and the forecast for the near future. In two workshops, we adapted the Australian concept of water sensitive urban design for the Italian context. The workshops highlighted that, in order to avoid the extreme consequences of events like droughts and floods cause, it is important to mitigate their impacts not only in emergencies but also on ordinary water management.

Interestingly, although the population is generally unaware of the impacts of the two latest severe drought events, these did stimulate a whole set of adaptation measures working towards a more sustainable use of water resources at municipal and regional level; that is, from the technical dimension to governance and from the individual to the community level. The role of citizens in planning has been increasing, and their responsible behaviour in terms of water consumption patterns is now valued as technical and technological measures. Local administrators are aware of the fact that all technical adaptation and mitigation measures would not have a significant impact if they did not come with awareness and information campaigns directed to citizens and local users in order to change their consumption patterns.

However, despite a move towards greener cities, drastic and definite changes in water management practices according to the concept of the integrated urban water management cycle and in line with WSUD principles have not been fully adopted yet, even though they would drastically minimise the ecological footprint of urban spaces.

Nevertheless, this article demonstrates how ordinary water management, which includes amongst other aspects, standard maintenance works to increase the network efficiency coupled with awareness raising campaigns for more sustainable consumption patterns involving citizens, is an effective preventive measure to significantly reduce the vulnerability of cities to extreme water crises.

The same drought, whose impact was marginal in Parma and Ferrara, caused havoc elsewhere, such as in tourism affecting the coast of Romagna which has water supplied by 
the Ridracoli dam. In 2007 the reservoir experienced a critical level of exploitation. Hence, the fact that the two cities in the study did not experience severe crises does not itself exclude the fact that other neighbouring areas had to adopt drastic emergency measures. It is important to consider the peculiar characteristics of each context before transferring lessons learnt from one area to another. In addition, this exercise highlights the importance of linking the water sector to other aspects of risk and vulnerability at city level, leading to a holistic WSUD approach.

Nevertheless, the best practice identified in both Parma and Ferrara presents high potential for replication in other cities. Future research should examine how to make WSUD operational in other urban contexts. Given that Ferrara and Parma are not positioned at the extreme end of the vulnerability spectrum for which the WSUD principles were developed, a next step will be to posit a methodology that would be appropriate for different parts of the urban water vulnerability spectrum.

Acknowledgements. The Authors wish to acknowledge the collaboration of the Emilia-Romagna Region and its Environmental Agency and the extensive support of the reviewer Prof. L. Rietveld. This research has been funded by the Water2Adapt project (http://www.feem-project.net/water2adapt/) with the financial support of the Italian Institute for Environmental Protection and Research (ISPRA).

Edited by: L. Rietveld

\section{References}

ATO2 Parma: Piano di Conservazione della Risorsa Idrica (proposal), ATO Parma, 2010.

ATO6 Ferrara: Il Piano di Conservazione della Risorsa, ATO Ferrara, 2006.

Brown, R. R. and Farrelly, M. A.: Advancing the Adoption of Diverse Water Supplies in Australia: A Survey of Stakeholder Perceptions of Institutional Drivers and Barriers, Report No. 07/04, National Urban Water Governance Program, Monash University, 2007.

Carrera, L., Mysiak, J., and Crimi, J.: Siccità nel bacino del Po: cause, impatti e possibili rimedi, Review of Environment, Energy and Economics, Fondazione Eni Enrico Mattei, 2013.

C40 Cities: www.c40cities.org (last access: 22 August 2011), 2011.

Ferrari, G. and Spina, A.: Personal communication of the authors with Gruppo Iren and ATO2 Parma, 31/05/2011, Parma, Italy, 2011.

IPCC: Glossary of Terms used in the IPCC Fourth Assessment Report, WG II, http://www.ipcc.ch/pdf/glossary/tar-ipcc-terms-en. pdf, 2001.

McAuley, A. and McManus, R.: Water sensitive urban design planning guide. Darwin Harbour WSUD Strategy. Northern Territory Department of Planning and Infrastructure, Australia, 2009.

Milman, A. and Short, A.: Incorporating resilience into sustainability indicators: An example for the urban water sector, Global Environ. Chang., 18, 758-767, 2008.

Provincia di Parma: Piano Territoriale di Coordinamento Provinciale, available at: http://ptcp.provincia.parma.it/ (last access: 30 September 2011), 2003.

The World Bank: Cities and climate change: an urgent agenda, World Bank, available at: http://siteresources. worldbank.org/INTUWM/Resources/340232-1205330656272/ CitiesandClimateChange.pdf (last access: 7 April 2014), 2010.

Wong, T. H. F.: An Overview of Water Sensitive Urban Design Practices in Australia, Water Practice and Technology, 10, 2006. 